\title{
Therapeutic Lifestyle Changes (TLCs) Improve the Quality of Life in the Elderly with Hypertension
}

\author{
Kuslan Sunandar, Tati Suheti, Achmad Husni \\ Health Polytechnic, Bandung, Indonesia \\ Email: Kuslan_sunandar@yahoo.com
}

How to cite this paper: Sunandar, K., Suheti, T. and Husni, A. (2016) Therapeutic Lifestyle Changes (TLCs) Improve the Quality of Life in the Elderly with Hypertension. Open Journal of Nursing, 6, 767775.

http://dx.doi.org/10.4236/ojn.2016.69077

Received: August 16, 2016

Accepted: September 26, 2016

Published: September 29, 2016

Copyright $\odot 2016$ by authors and Scientific Research Publishing Inc. This work is licensed under the Creative Commons Attribution International License (CC BY 4.0).

http://creativecommons.org/licenses/by/4.0/ (c) (i) Open Access

\begin{abstract}
Hypertension was one of the most serious diseases that affect many people in Indonesia in the age group of 18 years old and above. Hypertension can affect the quality of life, especially for the elderly, so the quality of life for the elderly will be disrupted and the life expectancy of elderly people will also decrease. Elderly people who have a good quality of life will have inner satisfaction, which can be judged from the physical, psychological and social aspects. This study only measured the quality of life of physical dimensions, especially blood pressure (systolic and diastolic). Improved quality of life of people with hypertension can be pursued with behavioral changes that increase blood pressure. One way can be given is the Therapeutic Lifestyle Changes (TLCs). The aim of this study was to determine the effect of the Therapeutic Lifestyle Changes (TLCs) on improving the quality of life of the elderly with hypertension in Puskesmas Pasirkaliki Bandung. This research is a quasi-experimental design with two group pre-post tests with control group. The statistical test used Wilcoxon test and Mann Whitney with a standard error of $5 \%$ or $\alpha=0.05$, because the data distribution was not normal. In the total sample, there were 52 respondents who had hypertension. Therapeutic Lifestyle Changes (TLCs) was done once a week for 4 weeks. The results prove that there is a statistically significant difference in systolic and diastolic blood pressure (quality of life) $(\mathrm{Z}=-4.415 ; \mathrm{Z}=-4.208 \mathrm{p}<0.05)$. It is advisable for people with hypertension to expect to remain consistent in the Therapeutic Lifestyle Changes (TLCs) in their activity of daily life.
\end{abstract}

\section{Keywords}

Therapeutic Lifestyle Changes in Hypertension

\section{Background}

Hypertension is a problem in the elderly because it is often found to be a major factor 
in heart failure and coronary disease. More than half the deaths over the age of 60 years old are due to heart and cerebrovascular diseases. Hypertension in the elderly is divided into two types: the first one is with increased systolic and diastolic pressure commonly in middle age, whereas the second is the systolic hypertension found in over 65 years old [1].

The prevalence of hypertension in Indonesia obtained through measurement at age $\geq 18$ years old was 25.8 percent, the highest in Bangka Belitung (30.9\%), followed by South Kalimantan (30.8\%), East Kalimantan (29.6\%) and Java west (29.4\%). The prevalence of hypertension in the city based on the number of patients who went to the clinic was $12.10 \%$, ranks second out of 20 diseases. In the sub-district Puskesmas Pasirkaliki Cicendo Bandung in November 2013, hypertensive disease was ranked first by the number of hypertensive patients seeking treatment at health centers, which was as many as 550 people [2] [3].

High blood pressure in the long term will damage the arterial endothelium and accelerate atherosclerosis. Complications of hypertension include damage of organs such as the heart, eyes, kidneys, brain and major blood vessels. If the patient has hypertension and cardiovascular disease, the morbidity and mortality of the cardiovascular disorders will be increased. According to the Framingham study, patients with hypertension have an increased risk for coronary disease significantly, stroke, peripheral artery disease, and heart failure [4].

In the elderly the risk of hypertension increases, and it is caused by natural changes in the heart, blood vessels and hormones. The change is accompanied by other factors that can trigger the occurrence of hypertension [5]. Hypertension which occurs in the elderly is a prolonged illness and brings the complex effects for the sufferer. While not all kinds of hypertension constitute a life-threatening disease, it would be also an economic burden for individuals, families, and communities as a whole. Hypertension will lead to medical, social and psychological problems that would restrict the activities of the elderly, which will cause a decrease in quality of life [6].

The problems that arise as a result of hypertensive disease are affecting the ability of the elderly to live independently. Due to functional impairment of the body, the problems can hinder everyday activities such as bathing regularly, preparing meals independently, or performing activities outside the home, thus affecting the quality of life. The presence of hypertension among the elderly poses a risk of functional decline in the elderly population and can affect the quality of life of the elderly [7].

In order to assess the quality of life that is appropriate for the elderly receiving nursing care, this model can be used as a guideline. Issues surrounding the quality of life of the elderly are very broad, but researchers will discuss four specific issues that have a major impact on QOL domain. The problem has a capacity which affects all domains, including psychological health domain for the elderly, the pain, the spirituality of parents and social domain.

The WHO assessment of the quality of life for adults (WHOQOL-OLD) was originally developed by the WHOQOL group to examine the quality of life of the elderly. 
This assessment consists of six aspects: sensory abilities, autonomy, activities past, present and future, social participation, thinking about death and the state of the terminal as well as friendship and love [8].

Based on the results of preliminary studies by observation and interviews of five elderly people in Posbindu RW 07 Baladewa Bandung in January 2015, all the elderly with hypertension have the limitations of daily activities, so special attention is needed in addressing the quality of life of the elderly. Behavior modification or lifestyle in elderly is expected to be able to adapt to the state of the disease and control the impact that may arise. One model modification that can be done is the Therapeutic Lifestyle Changes (TLCs). To the researchers, interventions will be provided to the elderly on a visit so that the effects of interventions for the elderly could be seen during a visit to Posbindu.

\section{Material and Methods}

This research method uses Quasi Experiment with the design of two groups of pre and post test with control.

This research was conducted in Posbindu Pasirkaliki Baladewa Padjadjaran District of Cicendo Bandung. This research was conducted in October 2015 after obtaining ethical approval from the local ethics committee.

Research Samples:

Samples in this study were elderly people who regularly followed the Posbindu activities.

The number of samples in this study is 26 in intervention group and 26 in control group, which includes a total of 52 respondents. The sampling techniques on research conducted by the non-random purposive sampling, with the inclusion criteria were as follows:

a). Elderly with mild to moderate hypertension.

b). Elderly uninterrupted physical activity.

c). Elderly able to hear and speak clearly.

d). Elderly cooperative and willing to become respondents.

While the exclusion criteria in the study are:

1). Elderly people who already have experience to diet and exercise regularly.

2). The elderly who do not regularly come to Posbindu.

3). Elderly who has a hearing impairment.

The data collection procedure is as follows:

1. Identify elderly who meet the inclusion criteria both in the intervention and control group.

2. Elderly who meet these criteria are given an explanation (informed consent) and seek approval for the respondent.

3. After obtaining the agreement of the respondent then measuring the blood pressure (quality of life) either the intervention group or the control group.

4. Once identified the quality of life of elderly given intervention model of Therapeu- 
tic Lifestyle Changes (TLCs), this intervention is done once a week for four weeks, while the control group did not do the application of the model Therapeutic Lifestyle Changes (TLCs) but only given standard care in Posbindu.

5. To maintain the principle of justice for the sample, then the control group after the blood pressure measurement prior to the intervention (pre-test) was given a leaflet on diet and physical activity of patients with hypertension, then given them the opportunity to read for 1 hour. Blood pressure measurements after the intervention (post-test) in the intervention group and the control is done serially according to the stages of intervention.

After the data is collected, it will be done editing, coding and tabulation, and then analyzed.

With the following phases:

Prior to further analysis, first test data normality and homogenity of variance.

The normality test results obtained data were not normally distributed, the nonparametric test, the Wilcoxon signed rank test to see the difference of the respective proportions and Mann Whitney $U$ test to compare the proportion of each difference between the intervention group and control group.

\section{Results and Discussion}

The results of this study are as follows.

a. Normality test.

Normality and homogeneity test is a prerequisite test before hypothesis test. Normality test that uses Kolmogorof-Smirnov indicate $\mathrm{p}<0.05$. This means that the distribution of the data on initial tests and final tests revealed abnormal. Base on the data, normality test recommended using bivariate test with the Wicoxon Paired test and the independent Mann Whitney test.

b. Hypothesis testing

Based on the results of the Wilcoxon test, in Table 1 showed that the interventon group there are differences in systolic and diastolic blood pressure (quality of life) is very significant in the value pretest and posttest $(Z=-4.415 ; Z=-4.208 p<0.05)$. The difference is shown by a significant difference in systolic blood pressure between pretest and posttest $(\mathrm{p}<0.05)$. The differences are indicated with a mean decrease of 20.25 $\mathrm{mmHg}$ (pre test $=144.81$; post test $=123.85$ ). Results of statistical analysis on diastolic blood pressure values of the same data also show that there is a very significant difference in diastolic blood pressure values between the pretest and posttest $(p<0.05)$. The differences are indicated by a decrease in the average value of diastolic blood pressure by $10 \mathrm{~mm} \mathrm{Hg}$ (pretest $=93.08$; posttest $=83.08$ ). Based on the analysis, it can be concluded that statistically the Therapeutic Lifestyle Changes (TLCs) effect on a decrease in systolic and diastolic blood pressure (improved quality of life).

Table 2 shows that the Wilcoxon test results there was no significant difference in quality of life between pretest and posttest $(\mathrm{z}=-1.890, \mathrm{p}>0.05)$. The results indicated by the absence of significant mean difference in systolic blood pressure between pretest 
Table 1. Effect of Therapeutic Lifestyle Changes (TLCs) in the intervention group.

\begin{tabular}{cccc}
\hline No. & Variable & z Value & p Value \\
\hline 1 & Systolic blood pressure before and after & -4.415 & 0.000 \\
2 & Diastolic blood pressure before and after & -4.208 & 0.000 \\
\hline
\end{tabular}

Table 2. Effect of Therapeutic Lifestyle Changes (TLCs) in the control group.

\begin{tabular}{cccc}
\hline No. & Variable & z Value & p Value \\
\hline 1 & Systolic blood pressure before and after & -3.207 & 0.001 \\
2 & Diastolic blood pressure before and after & -1.890 & 0.059 \\
\hline
\end{tabular}

and posttest $(\mathrm{p}>0.05)$. with a mean decrease of $4.6 \mathrm{mmHg}($ pretest $=140.77$; posttest $=$ 136.15). Based on the analysis, it can be concluded that statistically the Therapeutic Lifestyle Changes (TLCs) has no effect on blood pressure reduction (improved quality of life).

Effect of Therapeutic Lifestyle Changes (TLCs) in the intervention and the control group based on Mann Whitney test results in Table 3 show statistically the influence of the Therapeutic Lifestyle Changes (TLCs) towards improving the quality of life of patients with hypertension $(\mathrm{z}=-4.163 ;-4.372, \mathrm{p}<0.05)$.

Based on the analysis, it can be concluded that statistically the Therapeutic Lifestyle Changes (TLCs) effective in improving quality of life, blood pressure systolic and diastolic hypertension.

\section{Discussion}

Based on the analysis of data in the intervention group, it appears there is a significant difference in the reduction in systolic and diastolic blood pressure. The research results proved that Therapeutic Lifestyle Changes (TLCs) can lower blood pressure in hypertensive patients. Although these results are statistically proven to lower blood pressure, it does not mean people with hypertension do not need medical treatment again to lower the pressure, because in substance Therapeutic Lifestyle Changes (TLCs) has not been able to reduce blood pressure to the normal range of systolic blood pressure and diastolic in patients hypertension. The average systolic and diastolic blood pressure after TLCs still above the normal value $(130 ; 87.12)$, so as clearly TLCs intervention merely in the statistical analysis, while according substance they need be evidenced with more research further.

Therapeutic Lifestyle Changes (TLCs) is not the only way that can lower blood pressure, so that in certain circumstances, when the blood pressure is being increased significantly the hypertensive patients still need medical treatment in the form of drug therapy to lower blood pressure.

Other factors need is controlled by people with hypertension is a diet that with calorie intake and certain substances in the form of salt and physical activities like sports.

The decrease in blood pressure after getting Therapeutic Lifestyle Changes (TLCs) 
Table 3. Differences in systolic and diastolic blood pressures in the intervention and control groups before and after TLCs.

\begin{tabular}{cccc}
\hline No. & Variable & Nilai z & Nilai p \\
\hline 1 & Systolic blood pressure before TLCs & -1.146 & 0.252 \\
2 & Systolic blood pressure after TLCs & -4.163 & 0.000 \\
3 & Diastolic blood pressure before TLCs & -0.178 & 0.859 \\
4 & Diastolic blood pressure after TLCs & -4.372 & 0.000 \\
\hline
\end{tabular}

can be described as follows; that in the human nervous system are the central nervous system and the autonomic nervous system. The function of the central nervous system is controlling the movements that you want, such as the movement of the hands, feet, neck, and fingers. The autonomic nervous system serves to control the movements are automatic, such as the digestive system function, the function of the cardio-vascular system, endocrine system function including sexual arousal. The autonomic nervous system consists of a stand-alone subsystems that work in opposite, consisting of the sympathetic nervous system and the parasympathetic nervous system. The sympathetic nervous system is working to improve stimulation or stimulate the body's organs, stimulate increased heart rate and breathing, cause constriction of peripheral blood vessels and enlarged blood vessels center, lowers skin temperature and skin resistance, and will inhibit the function of the digestive system and sexual. Instead parasympathetic nervous system works to stimulate the decrease of all functions is increased by the sympathetic nervous system and stimulate the rise of all the functions derived by sympathetic nerves. During such systems are functioning normally and balanced, then the activity levels of the system that will inhibit or suppress the effects of other systems [9] [10].

The situation is influenced by the chemistry of body fluids (blood) levels of salt, cholesterol and others. In addition to the chemical levels in the blood, are affected by stress conditions. Therefore, in addition to lifestyle changes are closely related to diet, activity, rest and sleep. Patterns of activity and good sleep will restore the condition of the body so that it becomes more relaxed. In this relaxed state, the body will experience a resting phase. At that time, the body will activate the parasympathetic nervous system [10]-[12].

The working of the parasympathetic nervous system causes a decrease in heart rate, respiratory rhythm and blood pressure. Conversely, when the body is under stress or in uncomfortable conditions, the sympathetic nerves and muscles of the blood vessels to contract so that the cross-sectional diameter of small blood vessels decreases that resulted in an increase in blood pressure [9] [10].

The results of this study also showed that the drop in blood pressure in patients with hypertension have an impact on improving their quality of life both physically, psychologically, socially and comfort and the feeling in general [13]-[15]. Research has proven that blood pressure reduction causes an increase in the quality of life of patients with hypertension. Decreased blood pressure in the blood vessels in the head and caused a 
decline in brain stimulation to stimulation of pain and headaches suffered over the years. This condition indicates improved quality of life in the physical dimension and will certainly affect also the emotional and psychological conditions [16]-[18]. Research conducted by Baune et al. (2005) [9] states that all dimensions of quality of life that consists of psychological, physical, social and environmental statistically significant relationship with hypertension. In a relaxed state, the body through the brain will produce endorphrin which serves as the body's natural painkillers and can relieve pain (physical complaints).

Likewise psychological dimension, there will be the release of negative emotions such as anger, anxiety, and others that are the implications of increasing the quality of life of the psychological side. Patients with hypertension feel more able to control his emotions when facing things that are unpleasant and can provoke emotional reactions. Mood changes very volatile and unhappiness that usually accompanies the disease course of hypertension decreases. Change negative emotions into positive emotions turned out to cause a significant impact on the social life of people with hypertension. Relationships with others become better and more social activity started to run because of reduced pain during the time felt. Pain in the head can cause disruption of life for their patients with significant disabilities lose time to work and interact socially [19] [20]. Pain in the head can also degrade the quality of life of patients that can lead to large losses due to the economic terms loss number of working days and the amount of medical expenses to be incurred. All the changes that occur both from the physical, psychological and social is all dimension of quality of life. Research conducted by Soni concluded that there is a relationship between hypertension and decreased quality of life, which in the study stated that the elderly with hypertension was 4.6 times life is less qualified than the elderly who do not have hypertension. In hypertensive patients got worse quality of life in physical health dimension, i.e. $64.6 \%$ impaired physical functioning, $60.0 \%$ disruption in the physical role, and $60.4 \%$ suffered from health problems as a whole [21] [22].

\section{Conclusions}

Based on the results of statistical analysis that have been done, it can be concluded:

1. Statistically there are differences in systolic and diastolic blood pressure (quality of life); and the differences are very significant in the pretest and posttest values $(\mathrm{Z}=$ $-4.415 ; \mathrm{Z}=-4.208 \mathrm{p}<0.05)$.

2. Therapeutic Lifestyle Changes (TLCs) have an effect on improving the quality of life of patients with hypertension.

3. Interventions of Therapeutic Lifestyle Changes (TLCs) in patients with hypertension have effects on the reduction of blood pressure.

\section{Suggestions}

1. With evidence of the effectiveness of the Therapeutic Lifestyle Changes (TLCs), it is advisable in patients with hypertension to remain consistently in doing Therapeutic 
Lifestyle Changes (TLCs) in an effort to control blood pressure.

2. The cadres of Posyandu should continue to give health education with Therapeutic Lifestyle Changes (TLCs) to patients with hypertension in their respective areas.

\section{Acknowledgements}

1. The Director of the Department of Health Polytechnic Bandung and head of research unit which have sponsored research.

2. The Chairman of the Department of Nursing Polytechnic Bandung Health Ministry and staff who have supported this research activity.

3. The Chief Medical Officer of Bandung and the staff who have given permission for the implementation of this research.

4. The Cadres Padjadjaran Bandung village that has supported the implementation of this research activity.

\section{References}

[1] (1993) National High Blood Pressure Education Program Working Group Report on Primary Prevention of Hypertension. Archives of Internal Medicine, 153, 186-208. Cholesterol Education National Program, Detection, Evaluation, and Treatment of High Blood Cholesterol in Adults (Adult Treatment Panel III), the Third Report of the National Cholesterol on Education Program Expert Panel (NCEP). http://dx.doi.org/10.1001/archinte.1993.00410020042003

[2] Health Office Bandung City (2013) Health Profile Report of Bandung City. Health Office, Bandung.

[3] Ministry of Health (2014) The Results of the Health Research Ministry of Health RI 2013. Balitbangkes Ministry of Health Republik Indonesia.

[4] Ministry of Health RI (2006) Surveillance Epidemiology Practical Guide (PEP). DG PPM \& PL, R.I. Health Department, Jakarta.

[5] Pavlik, V.N., Hyman, D.J., Vallbona, C., Toronjo, C. and Louis, K. (1997) Hypertension Awareness and Control in an Inner-City African-American Sample. Journal of Human Hypertension, 11, 277-283. http://dx.doi.org/10.1038/sj.jhh.1000445

[6] Hypertension Prevention Trial Research Group (1990) The Hypertension Prevention Trial: Three-Year Effects of Dietary Changes on Blood Pressure. Archives of Internal Medicine, 150, 153-162. http://dx.doi.org/10.1001/archinte.1990.00390130131021

[7] Appel, L.J., Espeland, M.A., Easter, L., Wilson, A.C., Folmar, S. and Lacy, C.R. (2001) Effects of Reduced Sodium Intake on Hypertension Control in Older Individuals: Results from the Trial of Nonpharmacologic Interventions in the Elderly (TONE). Archives of Internal Medicine, 161, 685-693. http://dx.doi.org/10.1001/archinte.161.5.685

[8] World Health Organization (2006) Whoqol-Old Manual. European Office, Copenhagen.

[9] Baune, B.T., Aljeesh, Y.I. and Adrian, I. (2005) Predictores of Quality of Life among Patients with and without Hypertensive Stroke. Journal of the Islamic University of Natural Sciences Series, 13, 91-107.

[10] Appel, L.J., Champagne, C.M., Harsha, D.W., Cooper, L.S., Obarzanek, E., Elmer, P.J., Stevens, V.J., Vollmer, W.M., Lin, P.H., Svetkey, L.P., Stedman, S.W. and Young, R. (2003) Effects of a Comprehensive Lifestyle Modification on Blood Pressure Control: Main Results of the PREMIER Clinical Trial. JAMA, 289, 2083-2093. 
[11] Stamler, R., Stamler, J., Grimm, R., Gosch, F.C., Elmer, P., Dyer, A., Berman, R., Fishman, J., Van Heel, N., Civinelli, J. and McDonald, A. (1987) Nutritional Therapy for High Blood Pressure. Final Report of a Four-Year Randomized Controlled Trial-The Hypertension Control Program. JAMA, 257, 1484-1491. http://dx.doi.org/10.1001/jama.1987.03390110060027

[12] Intersalt Cooperative Research Group (1988) Intersalt: An International Study of Electrolyte Excretion and Blood Pressure. Results for 24-Hour Urinary Sodium and Potassium Excretion. BMJ, 297, 319-328. http://dx.doi.org/10.1136/bmj.297.6644.319

[13] Stamler, R., Stamler, J., Gosch, F.C., Civinelli, J., Fishman, J., McKeever, P., McDonald, A. and Dyer, A.R. (1989) Primary Prevention of Hypertension by Nutritionalhygienic Means. Final Report of a Randomized, Controlled Trial. JAMA, 262, 1801-1807. http://dx.doi.org/10.1001/jama.1989.03430130077038

[14] Chobanian, A.V., Bakris, G.L., Black, H.R., Cushman, W.C., Green, L.A., Izzo Jr., J.L., Jones, D.W., Paterson, N.J., Oparil, S., Wright Jr., J.T. and Roccella, E.J. (2003) Seventh Report of the Joint National Committee on Prevention, Detection, Evaluation, and Treatment of High Blood Pressure. Hypertension, 42, 1206-1252. http://dx.doi.org/10.1161/01.HYP.0000107251.49515.c2

[15] Knight, E.L., Bohn, R.L., Wang, P.S., Glynn, R.J., Mogun, H., Avorn, J. (2001) Predictors of Uncontrolled Hypertension in Ambulatory Patients. Hypertension, 38, 809-814. http://dx.doi.org/10.1161/hy0901.091681

[16] Ostchega, Y., Yoon, S.S., Hughes, J. and Louis, T. (2008) Hypertension Awareness, Treatment and Control-Continued Disparities in Adults: United States, 2005-2006. In: NCHS Data Bried, Vol. 3, National Center for Health Statistics, Hyattsville.

[17] The Trials of Hypertension Prevention Collaborative Research Group (1997) Effects of Weight Loss and Sodium Reduction Intervention on Blood Pressure and Hypertension Incidence in Overweight People with High Normal Blood Pressure. The Trials of Hypertension Prevention, Phase II. Archives of Internal Medicine, 157, 657-667. http://dx.doi.org/10.1001/archinte.1997.00440270105009

[18] Stevens, V.J., Obarzanek, E., Cook, N.R., Lee, I.M., Appel, L.J., Smith West, D., Milas, N.C., Mattfeldt-Beman, M., Belden, L., Bragg, C., Millstone, M., Raczynski, J., Brewer, A., Singh, B. and Cohen, J. (2001) Long-Term Weight Loss and Changes in Blood Pressure: Results of the Trials of Hypertension Prevention, Phase II. Annals of Internal Medicine, 134, 1-11. http://dx.doi.org/10.7326/0003-4819-134-1-200101020-00007

[19] Wong, M.D., Shapiro, M.F., Boscardin, W.J. and Ettner, S.L. (2002) Contribution of Major Diseases to Disparities in Mortality. The New England Journal of Medicine, 347, 15851592. http://dx.doi.org/10.1056/NEJMsa012979

[20] Mensah, G.A., Mokdad, A.H., Ford, E.S., Greenlund, K.J. and Croft, J.B. (2005) State of Disparities in Cardiovascular Health in the United States. Circulation, 111, 1233-1241. http://dx.doi.org/10.1161/01.CIR.0000158136.76824.04

[21] Appel, L.J., Moore, T.J., Obarzanek, E., Vollmer, W.M., Svetkey, L.P., Sacks, F.M., Bray, G.A., Vogt, T.M., Cutler, J.A., Windhauser, M.M., Lin, P.H. and Karanja, N. (1997) A Clinical Trial of the Effects of Dietary Patterns on Blood Pressure. DASH Collaborative Research Group. The New England Journal of Medicine, 336, 1117-1124. http://dx.doi.org/10.1056/NEJM199704173361601

[22] Pavlik, V.N., Hyman, D.J. and Vallbona, C. (1996) Hypertension Control in Multi-Ethnic Primary Care Clinics. Journal of Human Hypertension, 10, S19-S23. 
Submit or recommend next manuscript to SCIRP and we will provide best service for you:

Accepting pre-submission inquiries through Email, Facebook, LinkedIn, Twitter, etc. A wide selection of journals (inclusive of 9 subjects, more than 200 journals)

Providing 24-hour high-quality service

User-friendly online submission system

Fair and swift peer-review system

Efficient typesetting and proofreading procedure

Display of the result of downloads and visits, as well as the number of cited articles

Maximum dissemination of your research work

Submit your manuscript at: http://papersubmission.scirp.org/

Or contact ojn@scirp.org 